\title{
Metabotropic Glutamate 5 Receptor Blockade Alleviates Akinesia by Normalizing Activity of Selective Basal-Ganglia Structures in Parkinsonian Rats
}

\author{
Nathalie Breysse, ${ }^{1}$ Marianne Amalric, ${ }^{1}$ and Pascal Salin ${ }^{2}$ \\ ${ }^{1}$ Laboratoire de Neurobiologie de la Cognition and ${ }^{2}$ Laboratoire de Neurobiologie Cellulaire et Fonctionnelle, Centre National de la Recherche Scientifique, \\ 13402 Marseille, France
}

\begin{abstract}
Glutamate overactivity within the basal ganglia has been shown to be central to the expression of motor symptoms in advanced stages of Parkinson's disease, and metabotropic glutamate receptors (mGluRs) represent promising targets for new therapeutic strategies in this pathology. Little is known, however, about the cellular and behavioral changes occurring in the early stages of the disease when dopamine depletion is moderate. Here, we report that rats with partial bilateral dopamine lesions exhibit akinetic deficits associated with dramatically increased neuronal metabolic activity in selective structures of the basal ganglia such as the subthalamic nucleus and the substantia nigra pars reticulata, but not in the entopeduncular nucleus. Furthermore, chronic treatment with the mGluR5 antagonist 2-methyl-6-(phenylethylnyl)pyridine alleviated the akinesia and was associated with a normalization of the activity of these two overactive structures. These data stress the therapeutic potential of mGluR5 antagonists in the treatment of parkinsonian patients in the early stages of the disease.
\end{abstract}

Key words: Parkinson's disease; MPEP; reaction time task; in situ hybridization; glutamate decarboxylase; cytchrome oxydase

\section{Introduction}

In Parkinson's disease (PD), the progressive degeneration of dopamine (DA) neurons induces a series of changes in basal ganglia circuitry that underlie the origin of the clinical symptoms, including akinesia, resting tremor, and rigidity. According to the classical model of basal ganglia circuitry (DeLong, 1990), the DA neuronal loss leads to hyperactivity of the subthalamic nucleus (STN), which provides an increased glutamatergic excitatory drive onto the internal part of the globus pallidus [(GPi) equivalent to the rodent entopeduncular nucleus (EP)] and substantia nigra pars reticulata $(\mathrm{SNr})$. Because of the severe complications associated with conventional dopaminergic therapies, counteracting glutamatergic hyperactivity by surgical inactivation of the STN or pharmacological blockade of glutamate transmission represents the most recent challenge in the treatment of PD (Benabid et al., 2000; Chase and Oh, 2000; Rouse et al., 2000). Pharmacological attempts to reduce excessive glutamate activity in animal models of PD were realized via blockade of ionotropic glutamate receptors (Greenamyre and O'Brien, 1991; Baunez et al., 1994; Ossowska et al., 1994, 1996; Lorenc-Koci et al., 1998), but with only limited success because of considerable side effects (hallucinations, cognitive perturbations, postural imbalance) (Schmidt, 1994; Amalric et al., 1995a; Starr, 1995). Targeting the

Received March 25, 2003; revised July 7, 2003; accepted July 17, 2003.

This work was supported by the Centre National de la Recherche Scientifique and by the Fondation de France (M.A). N.B. was supported by the Fondation pour la Recherche Médicale and by Institut Lilly. We are grateful to Dr. Fabrizio Gasparini (Novartis Pharma AG, Basel, Switzerland) for the generous gift of MPEP. We also acknowledge Drs. Lydia Kerkerian-Le Goff and Barry J. Everitt for critical reading and very helpful comments on this manuscript.

Correspondence should be addressed to Dr. Marianne Amalric, Laboratoire de Neurobiologie de la Cognition, Centre National de la Recherche Scientifique, 31 chemin J. Aiguier, 13402 Marseille cedex 20, France. E-mail: amalri@@ncf.cnrs-mrs.fr.

Copyright $\odot 2003$ Society for Neuroscience $\quad 0270-6474 / 03 / 238302-08 \$ 15.00 / 0$ metabotropic glutamate receptors (mGluRs) provides an alternative way of reducing glutamate hyperactivity, given their modulatory action via second messenger cascades. Because of its strategically interesting expression pattern within the basal ganglia, the mGluR5 subtype has recently emerged as a serious target for the pharmacological treatment of PD (Rouse et al., 2000). For instance, experimental studies in rats have shown that the selective mGluR5 antagonist 2-methyl-6-(phenylethylnyl)-pyridine (MPEP) may have anti-parkinsonian effects in rodent models of PD involving either extensive DA lesions or pharmacological blockade of DA receptors (Gasparini et al., 1999; Spooren et al., 2000; Ossowska et al., 2001). We have also provided evidence that chronic, but not acute, treatment with MPEP alleviates motor executive deficits in an operant task (Breysse et al., 2002). However, the cellular basis of MPEP treatment and its therapeutic potential in earlier stages of the disease, characterized by moderate striatal DA denervation, remain unknown.

The aim of the present study was, therefore, to investigate, in a model involving partial dopaminergic lesions of the striatum, the relationship between motor deficits, the effects of MPEP treatment, and the changes in neuronal metabolic activity within the STN and its main target structures. This was achieved by testing lesioned animals in the execution of an operant reaction-time task and subsequently processing their brains to measure mRNA expression of the metabolic markers cytochrome oxydase subunit I (CoI) and GAD67 in the different structures.

\section{Materials and Methods \\ Behavioral procedure}

Male Wistar rats, weighing 110-120 gm at the beginning of the experiment, were housed in groups of two per cage and maintained under a 12 hr light/dark cycle (7:00 A.M. to 7:00 P.M., lights off). Their food supply was restricted to $15-17 \mathrm{gm} /$ day per rat, to keep them at $80 \%$ of the 
free-feeding weight of control animals. Water was provided ad libitum. All procedures were conducted in accordance with the requirements of the French Ministère de l'agriculture et de la pêche Décret (number 87-848; October 19, 1987).

\section{Behavioral test}

Rats were placed in an operant box (Campden Instruments, Cambridge, UK) and trained to release a lever after the onset of a conditioned visual stimulus (a light located above the lever) in a reaction time (RT) task. Details of the experimental procedure have been published previously (Amalric et al., 1993). Briefly, animals were conditioned to depress a lever and wait for the onset of the visual trigger stimulus presented after four randomly and equiprobably generated intervals $(0.50,0.75,1.00$, and $1.25 \mathrm{sec}$ ). To be rewarded by a $45 \mathrm{mg}$ food pellet (Phymep, Paris, France), the rat had to release the lever as fast as possible with a RT below 600 msec. The RT was taken to be the time elapsing from the stimulus onset to the lever release. Each daily session (lasting between 15 and $30 \mathrm{~min}$ ) ended after 100 trials. Performance was evaluated by measuring correct responses, incorrect (nonrewarded) responses when the lever was released with RTs longer than $600 \mathrm{msec}$, and RTs. After stabilization of optimal baseline (2-3 months), performance was recorded for 6 consecutive preoperative days. After a 1 week postoperative period, rats were then tested daily for 24 sessions up to $32 \mathrm{~d}$ after surgery.

\section{Surgery and drugs}

A bilateral 6-OHDA lesion was performed in anesthetized animals [intramuscular injections of xylazine $(15 \mathrm{mg} / \mathrm{kg})$ and ketamine $(100 \mathrm{mg} /$ $\mathrm{kg}$ )]. Rats were placed in a stereotaxic instrument (David Kopf Instruments) with the incisor bar positioned $-3.0 \mathrm{~mm}$ under the interaural line for surgical procedures based on the coordinates of Paxinos and Watson (1986). Forty-five animals received a bilateral injection of 6-OHDA [Sigma-Aldrich, Lyon, France; $4 \mu \mathrm{g} / \mu \mathrm{l}, 3 \mu \mathrm{l}$ per side over 9 min, or vehicle (ascorbic acid solution, $0.1 \mathrm{mg} / \mathrm{ml}$ in $0.9 \%$ saline)] in the dorsal striatum at the following coordinates: $\mathrm{AP}+0.2 \mathrm{~mm}, \mathrm{~L} \pm 3.5 \mathrm{~mm}$, DV $-4.8 \mathrm{~mm}$ (from skull) according to bregma. MPEP hydrochloride (Novartis, Basel, Switzerland) was dissolved in distilled water and injected intraperitoneally in a volume of $1 \mathrm{ml} / \mathrm{kg}$. The effects of the lesion were tested between postoperative days 9 and 14 for six consecutive sessions. The lesion group was then divided into five groups, depending on the dose of MPEP tested ( $0 \mathrm{mg} / \mathrm{kg}$ MPEP, $n=7 ; 0.75 \mathrm{mg} / \mathrm{kg}$ MPEP, $n=7 ; 1.5 \mathrm{mg} / \mathrm{kg}$ MPEP, $n=6 ; 3 \mathrm{mg} / \mathrm{kg}$ MPEP, $n=9 ; 6 \mathrm{mg} / \mathrm{kg} \mathrm{MPEP}$, $n=10)$. Because our previous results clearly showed that MPEP was effective after a chronic treatment only, rats were treated daily and tested for 3 weeks (days 15-32 after surgery) a few minutes before behavioral testing.

\section{Cellular procedure}

Animals were killed immediately after the last behavioral session $(1 \mathrm{hr}$ after the last injection). The brains were then quickly removed, frozen in dry ice, and kept at $-80^{\circ} \mathrm{C}$ until cryostat sectioning. Coronal $(10 \mu \mathrm{m}$ thick) tissue sections were cut at $-20^{\circ} \mathrm{C}$ at the level of the striatum (between interaural coordinates AP, 10.2-9.2 mm; based on the stereotaxic atlas of Paxinos and Watson, 1986), EP (AP, 6.44-6.00), SNr (AP, $4.20-3.20$ ), and STN (AP, 5.40-4.70). The sections were then mounted onto SuperFrost plus glass slides (Fisher Scientific, Elancourt, France). Tissue sections were stored at $-80^{\circ} \mathrm{C}$ until specific treatment.

The loss of DA terminals in the striatum was assessed as an index of the extent of the DA denervation by analysis of ${ }^{3} \mathrm{H}$-mazindol binding to DA uptake sites, as described previously (Javitch et al., 1985; Salin et al., 1996). Briefly, brain sections were air-dried and rinsed for $5 \mathrm{~min}$ in 50 $\mathrm{mm}$ Tris buffer with $120 \mathrm{~mm} \mathrm{NaCl}$ and $5 \mathrm{~mm} \mathrm{KCl}$. They were then incubated for 40 min with $15 \mathrm{~nm}\left[{ }^{3} \mathrm{H}\right]$-mazindol (NEN DuPont; specific activity, $17 \mathrm{Ci} / \mathrm{mm}$ ) in $50 \mathrm{~mm}$ Tris buffer containing $300 \mathrm{~mm} \mathrm{NaCl}$ and 5 $\mathrm{mm} \mathrm{KCl}$ added with $0.3 \mathrm{~mm}$ desipramine to block the noradrenalin uptake sites. Sections were rinsed twice for $3 \mathrm{~min}$ in the Tris incubation buffer and for $10 \mathrm{sec}$ in distilled water and were air dried. Autoradiographs were generated by apposing the sections to ${ }^{3} \mathrm{H}$-sensitive screen (Raytest, Courbevoie, France) for $7 \mathrm{~d}$ and were further quantified with a beta imager (Fuji-Bas 5000). The lack of the mazindol labeling was first determined in the dorso-lateral part of the striatum in lesioned rats and compared with control animals. An overall evaluation of the DA depletion was further assessed on the whole striatum.

\section{In situ hybridization}

Radiolabeled antisense synthetic DNA probe (43 mer) was used for GAD67 in situ hybridization, as described previously (Lievens et al., 1997). Briefly, the oligoprobes were 3 ' end-labeled by terminal deoxynucleotide transferase (Roche, Meylan, France) with ${ }^{35}$ S-dATP (1300 $\mathrm{Ci} / \mathrm{mmol}$; NEN Life Science Products). The probes were then purified from unincorporated nucleotides on Sephadex minispin columns (Roche). A radiolabeled antisense RNA probe was used for CoI mRNA detection. The cDNA, corresponding to nucleotides 5308-6218 within the gene coding for $\mathrm{CoI}$ of the rat mitochondrial genome (European Molecular Biology Organization databank reference number MIRNXX), was generously provided by Dr. E. Hirsch (Paris, France) (Vila et al., 2000). The antisense RNA probe was transcribed from $1 \mu \mathrm{g}$ of linearized plasmid containing the cDNA fragment, using a T7 polymerase, $2.5 \mathrm{~mm}$ ${ }^{35} \mathrm{~S}$-UTP $(1200 \mathrm{Ci} / \mathrm{mmol})$ with ATP, CTP, and GTP in excess. Slidemounted sections were postfixed for $5 \mathrm{~min}$ in $3 \%$ paraformaldehyde, incubated for $30 \mathrm{~min}$ in prehybridization buffer $(2 \times$ SSC and $1 \times$ Denhardt's solution), and acetylated for $10 \mathrm{~min}$ with $0.25 \%$ acetic anhydre in $0.1 \mathrm{~m}$ triethanolamine. Then, the tissue was treated for $30 \mathrm{~min}$ with $0.1 \mathrm{M}$ Tris-glycine, dehydrated, and air dried. When using oligoprobes, each section was covered with $35 \mu$ l of hybridization buffer ( $50 \%$ formamide, $1 \times$ Denhardt's, $1 \%$ yeast tRNA, $1 \%$ sheared salmon sperm DNA, $10 \%$ dextran sulfate, and $4 \times$ SSC) containing $20 \mathrm{nmol}$ of radiolabeled probe $(\sim 400,000 \mathrm{cpm})$ and incubated for $12-14 \mathrm{hr}$ at $42^{\circ} \mathrm{C}$ in humid chambers. After hybridization, the sections were washed sequentially in $1 \times$ SSC for $1 \mathrm{hr}$ at room temperature, $1 \times \mathrm{SSC}$ for $1 \mathrm{hr}$ at $42^{\circ} \mathrm{C}$, and $0.1 \times$ SSC for $1 \mathrm{hr}$ at $42^{\circ} \mathrm{C}$. For riboprobe, each section was covered with $20 \mu \mathrm{l}$ of the same hybridization buffer containing $6 \mathrm{ng}$ of CoI probe $\left(\sim 2.5 \times 10^{6} \mathrm{cpm}\right)$ and incubated for $4 \mathrm{hr}$ at $50^{\circ} \mathrm{C}$. Posthybridization treatments included washes at $52^{\circ} \mathrm{C}$ with $50 \%$ formamide in $2 \times$ SSC and incubation with RNase A $(100 \mu \mathrm{g} / \mathrm{ml})$ in $2 \times \mathrm{SSC}$ at $37^{\circ} \mathrm{C}$ for $30 \mathrm{~min}$. In both cases, the sections were then dehydrated and apposed to Kodak BioMax MR (Kodak, Rochester, NY) films in light-tight cassettes for 2-10 d. Sections processed for cellular analysis were thereafter coated with Amersham LM1 autoradiographic emulsion and exposed at $4^{\circ} \mathrm{C}$ for $5 \mathrm{hr}$ (CoI detection) and for 10-15 hr (GAD67 mRNA detection). Exposed slides were developed in Kodak D-19 for $4 \mathrm{~min}$ at $13^{\circ} \mathrm{C}$ and counterstained with toluidine blue. Brain sections from the experimental groups of animals and corresponding to each structure (three sections per animal) were run in the same in situ hybridization session.

\section{Data analysis}

Behavioral analysis. The mean of correct and delayed responses, averaged on each prelesion and postlesion session, were subjected to a two-factor ANOVA (control and lesion group was the independent factor and presurgery and postsurgery sessions the dependent factor). The effects of chronic MPEP treatment at different doses tested were analyzed previously on a day-to-day basis and clearly showed that a 3 week treatment was necessary for a full recovery of preoperative performance (Breysse et al., 2002). Consequently, MPEP-induced effects were assessed on the percentage of delayed responses at the end of the chronic treatment (day 32 ) in all groups. Means obtained in each group of animals (control, 6-OHDA, $0.75 \mathrm{mg} / \mathrm{kg}$ MPEP, $1.5 \mathrm{mg} / \mathrm{kg}$ MPEP, $3 \mathrm{mg} / \mathrm{kg}$ MPEP, $6 \mathrm{mg} / \mathrm{kg}$ MPEP) were subjected to a one-way ANOVA. When significant effect was found, post hoc comparisons were made using the Scheffé's test for multiple group comparison. Mean RTs were also measured in selected groups (6-OHDA, $1.5 \mathrm{mg} / \mathrm{kg}$ MPEP, and $3 \mathrm{mg} / \mathrm{kg}$ MPEP) on a preoperative session and on postoperative days 14 and 32. Statistical differences were assessed by a one-way ANOVA. Appropriate post hoc comparisons were performed with Scheffé's test.

Cellular analysis. Analysis of GAD67 mRNA labeling in EP and $\mathrm{SNr}$ and CoI mRNA in the STN was done at the cellular level on emulsioncoated sections. Sections were observed under dark-field epi-illumination with an immersion $20 \times$ objective of a microscope connected to a CCD camera (COHU Inc., San Diego, CA), and the digitized images were transferred to the screen of a video monitor with a resulting magnifica- 

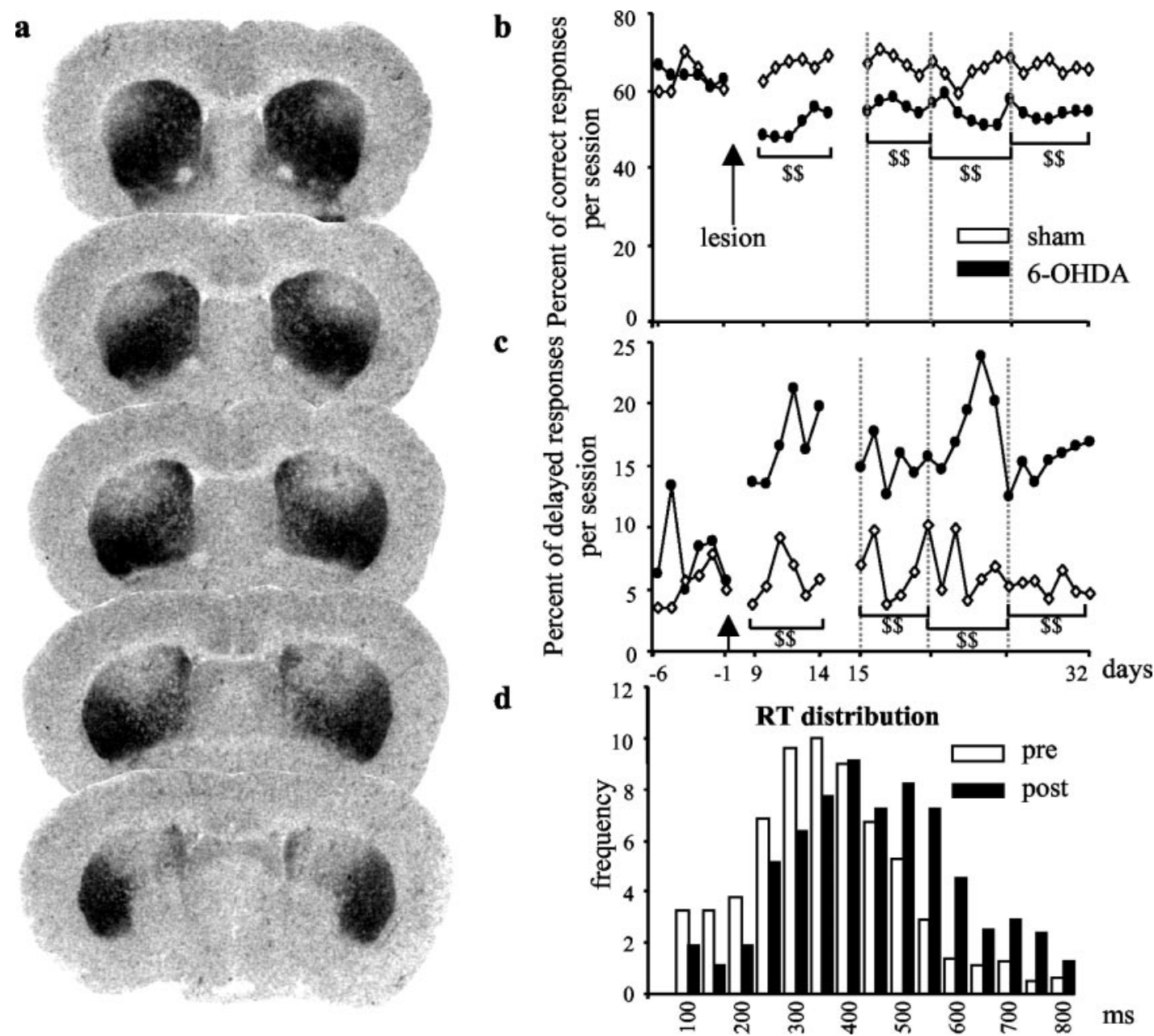

Figure 1. DA lesion extent and behavioral effects in the RT task. a, Digitized autoradiographic images of striatal ${ }^{3} \mathrm{H}$-mazindol binding to DA uptake sites showing the antero-posterior extent of the 6-OHDA-induced striatal denervation in a typical animal case. Note the partial and symmetrical loss of DA nerve terminals (lack of labeling) restricted to the dorsal striatum. $b, c$, Preoperative and postoperative performance of sham-operated $(n=6)$ and 6-OHDA-lesioned animals $(n=7)$ in the RT task for correct and delayed responses. The mean number of each type of responses per session is illustrated for six preoperative sessions (days -6 to -1 ) and 24 postoperative sessions (days $9-32$ ). Animals were tested every day in a 100 -trial session. As shown, the partial bilateral lesion induced a long-lasting effect in the RT task by reducing the level of correct responses $(b)$ and increasing the number of delayed responses ( $c$ ). $d$, Distribution of RTs (longer than $100 \mathrm{msec}$ and shorter than $800 \mathrm{msec}$ ) for one preoperative session (day -3) and one postoperative session (day 14). Each bar represents the mean number of RTs for all 6-0HDA-treated animals recorded by 50 msec intervals during the prelesion (white bars) and postlesion (black bars) session. DA depletion produced a shift toward long values of RTs. \$\$, Significant difference from sham group (treated no-lesioned animals; $p<0.001$; Scheffé's test after significant ANOVA).

tion of $1000 \times$. Using the Visioscan image analysis system (BIOCOM), the number of silver grains per cell was estimated under polarized light by measuring OD with respect to a standard curve of a defined number of silver grains. Two brain sections were quantified for each animal, and the mean number of silver grains per surface (for the STN and EP) or per neuron (for EP and SNr) was determined. The data from the different animals per condition were then averaged $(n=6-7$ for control group; $n=5-6$ for 6-OHDA group; $n=5-6$ lesioned-treated animals with $1.5 \mathrm{mg} / \mathrm{kg}$ MPEP; $n=8-9$ lesioned-treated animals with $3 \mathrm{mg} / \mathrm{kg} \mathrm{MPEP}$ ) and expressed as means \pm SEM. Results were presented as percentage of the corresponding mean control value. Statistical comparisons were performed for each anatomical structure using a one-way ANOVA, followed by Scheffé's test for multiple group comparison.

\section{Results}

\section{Behavioral effects}

Bilateral 6-OHDA infusion into the DA nerve terminals in the striatum produced a partial lesion restricted to the dorso-lateral part and extending over the whole rostro-caudal portion of the striatum (Fig. 1a). DA denervation in this model, measured by quantitative analysis of $\left[{ }^{3} \mathrm{H}\right]$ mazindol binding, reached a level of $60-80 \%$ in the dorsal area of the striatum and an average of $40-50 \%$ of the whole striata, which fits with the previously reported decrease in endogenous striatal DA contents assessed by HPLC (Amalric et al., 1995b). The behavioral effects of the partial bilateral 6-OHDA lesion were examined by testing the performance of rats previously trained to release a lever after the presentation of a visual cue within a RT limit for food reinforcement. Although partial, this type of lesion produced drastic and long-lasting effects in the RT task. A decrease in the percentage of correct responses was observed as early as $9 \mathrm{~d}$ after the lesion and lasted for over 32 postlesion days as compared with control and preoperative values (Fig. $1 b ; p<0.001$ for the four postoperative blocks of six sessions). The main deficit was expressed as an increase of delayed responses over the time limit (Fig. $1 c ; p<$ 0.001) and a shift to the right of the RTs distribution (Fig. 1d). In agreement with this, lengthening of RTs, which indexes the akinetic symptoms of the disease, has been observed previously in parkinsonian patients tested in similar tasks (Evarts et al., 1981).

A chronic (3 week) and systemic treatment with a selective 
a 25 Percent of delayed responses (D 32)

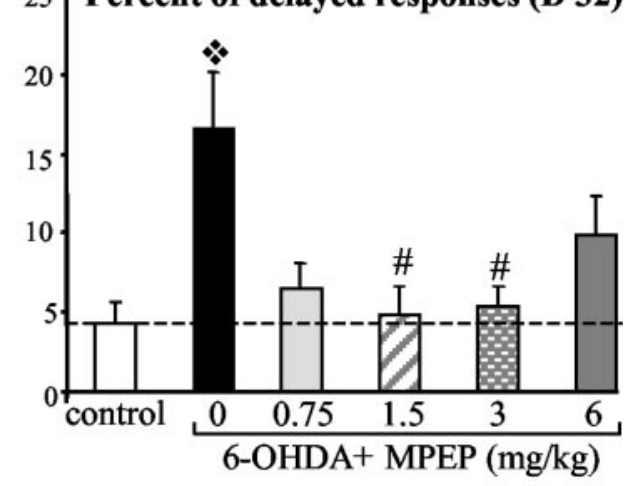

b

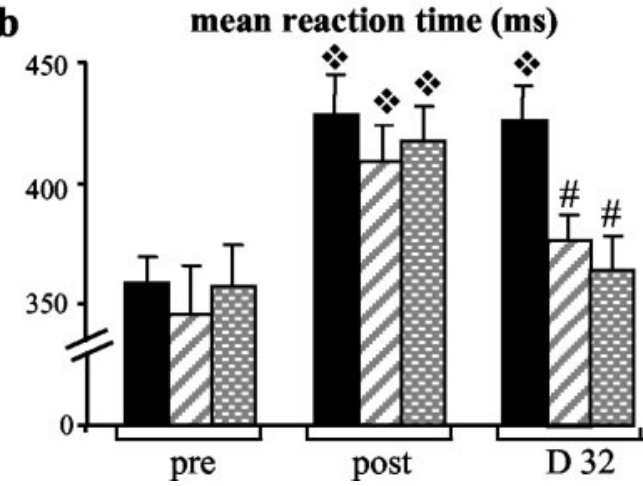

Figure 2. Effects of chronic MPEP treatment on behavioral parameters measured in the reaction time task. $a$, Percentage of delayed responses for each experimental group \pm SEM (sham, $n=6 ; 6-$ OHDA, $n=7 ; 0.75 \mathrm{mg} / \mathrm{kg}$ MPEP, $n=7 ; 1.5 \mathrm{mg} / \mathrm{kg} \mathrm{MPEP}, n=6 ; 3 \mathrm{mg} / \mathrm{kg}$ MPEP, $n=9 ; 6 \mathrm{mg} / \mathrm{kg} \mathrm{MPEP,} n=10$ ) measured for the last RT session (day 32). Whereas MPEP chronic treatment at the lowest and highest doses $(0.75$ and $6 \mathrm{mg} / \mathrm{kg}$ ) just partially improved recovery of performance, MPEP at doses of 1.5 and $3 \mathrm{mg} / \mathrm{kg}$ allowed a total recovery. Significant difference from control group ( $p<0.05$; Scheffé's test after significant ANOVA); \#, significant difference from 6-OHDA-nontreated group ( $p<0.05$; Scheffé's test after significant ANOVA). $b$, Mean RT \pm SEM for one preoperative session (day -1 ) and two postoperative sessions corresponding to the lesion effect without treatment (day 14) in comparison with the last day of chronic treatment (day 32) and measured for the 6-OHDA, $1.5 \mathrm{mg} / \mathrm{kg} \mathrm{MPEP}$, and 3 $\mathrm{mg} / \mathrm{kg}$ MPEP groups. At day 32, mean RTs were shortened by MPEP chronic treatment and significantly differed from the control-lesioned group injected with vehicle. $*$, Significant difference from preoperative performance for each group ( $p<0.05$; Scheffé's test after significant ANOVA); \#, significant difference from 6-OHDA group at D32 ( $p<0.05$; Scheffé's test after significant ANOVA).

antagonist of the receptor subtype mGluR5, MPEP, is able to alleviate the akinetic deficits produced by the DA lesion. MPEP at doses ranging from $0.75-6 \mathrm{mg} / \mathrm{kg}$ reversed the increase in delayed responses (over $600 \mathrm{msec}$ ) to reach the level of control group $32 \mathrm{~d}$ after the lesion ( $p<0.05$; Fig. $2 a$ ). When compared with the 6-OHDA group, only the doses of 1.5 and $3 \mathrm{mg} / \mathrm{kg}$ MPEP reached the level of significance and were selected for the remainder of this study. Moreover, mean RTs measured in a preoperative session for the three groups $(361,351$, and $350 \mathrm{msec}$ for 6-OHDA, $1.5 \mathrm{mg} / \mathrm{kg}$ 6-OHDA+MPEP, and $3.0 \mathrm{mg} / \mathrm{kg}$ 6-OHDA + MPEP, respectively) were lengthened after the lesion $(429,409$, and $418 \mathrm{msec}$ for the three groups, respectively; $p<$ 0.05 ), reaching on average $18 \%$ increase (Fig. $2 b$ ). Interestingly, mean RTs returned to preoperative values after MPEP treatment (377 and $364 \mathrm{msec}$ in $1.5 \mathrm{mg} / \mathrm{kg} 6-\mathrm{OHDA}+\mathrm{MPEP}$ and $3.0 \mathrm{mg} / \mathrm{kg}$ 6-OHDA+MPEP groups, respectively) and were found to significantly differ from the 6-OHDA group (426 msec; $p<0.05)$.

\section{Cellular effects}

To further characterize the cellular bases of the deficits, we examined the effects of the lesion on gene expression of markers of neuronal metabolic activity in the STN and its output structures SNr and EP by means of in situ hybridization histochemistry after completion of the behavioral test. Intraneuronal levels of CoI mRNA were measured as an index of metabolic activity of STN neurons. Neurons in the SNr and EP being mostly GABAergic, their metabolic activity was assessed by measuring gene expression of GAD67. The partial bilateral lesion of nigrostriatal afferents induced an increase in intraneuronal CoI mRNA levels $(+47 \%$; $p<0.05)$ in the STN (Fig. 3), paralleled by an increase in GAD67 mRNA levels (+27\%; $p<0.01)$ in SNr neurons (Fig. 4a). Unexpectedly, however, no significant change in GAD67 mRNA levels was measured in the medial part of the EP (Fig. $4 b$ ). In line with this, preliminary data showed that no significant change in CoI mRNA levels was observed after 6-OHDA lesions in the EP.

To test the hypothesis that the effects of the DA lesion may involve overactive glutamate transmission through mGluR5, we investigated whether the chronic MPEP treatment, at doses efficient to counteract the akinesia ( 1.5 and $3 \mathrm{mg} / \mathrm{kg}$ MPEP), could antagonize the cellular dysfunctions induced by the DA lesion in the same animals. MPEP treatment at a dose of $1.5 \mathrm{mg} / \mathrm{kg}$ totally reversed the DA lesion-induced increases in CoI mRNA levels in the STN (Fig. 3; $p<0.01$ ) and in GAD67 mRNA levels in the SNr (Fig. $4 a ; p<0.01$ ). At $3 \mathrm{mg} / \mathrm{kg}$, MPEP also reversed the lesioninduced increase in GAD67 mRNA levels in the $\mathrm{SNr}(p<0.01)$ but only partially antagonized the increase in CoI gene expression in STN neurons (Figs. $4 a$ and 3, respectively). Although the values obtained in this condition were not significantly reduced compared with those measured in animals with the lesion alone, they reached, however, the control level. Interestingly, MPEP treatment induced an increase in GAD67 mRNA expression in neurons of the EP compared with the values obtained in control or DA-lesioned animals, which reached significance only for the dose of $1.5 \mathrm{mg} / \mathrm{kg}$ ( $p<0.05$; Fig. $4 b)$. A parallel increase in CoI mRNA expression was observed in the EP at both doses of MPEP (preliminary data).

To further identify the structures that may play a central role in the expression of akinesia, we examined the cellular changes in the STN, SNr, and EP as a function of the level of akinesia in individual animals evaluated previously in the RT task after DA depletion with or without subsequent MPEP treatment. Akinesia was expressed as the percentage of change in the number of delayed responses, and changes in metabolic activity as percentage of control (sham operated). Expression of akinesia was found to be significantly correlated with changes in gene expression of CoI in the STN $\left(R^{2}=0.543 ; p<0.001\right)$ and in GAD67 in the $\operatorname{SNr}\left(R^{2}=\right.$ $0.563 ; p<0.001$ ). No correlation was observed in the EP (Fig. 5).

\section{Discussion}

Here, we demonstrate that bilateral and partial striatal DA depletion produces akinetic deficits in a RT task and thereby represents a relevant model of the early stages of DA nigrostriatal degeneration in PD patients. Under these conditions, a 3 week period of treatment with the mGluR5 antagonist MPEP significantly improved the akinesia. This beneficial effect was related to a reversal of the enhanced activity in the STN and the SNr as shown by a significant reduction in CoI mRNA and GAD67 mRNA expression, respectively, in the two structures of the basal ganglia thought to play a key role in the expression of PD symptoms. 


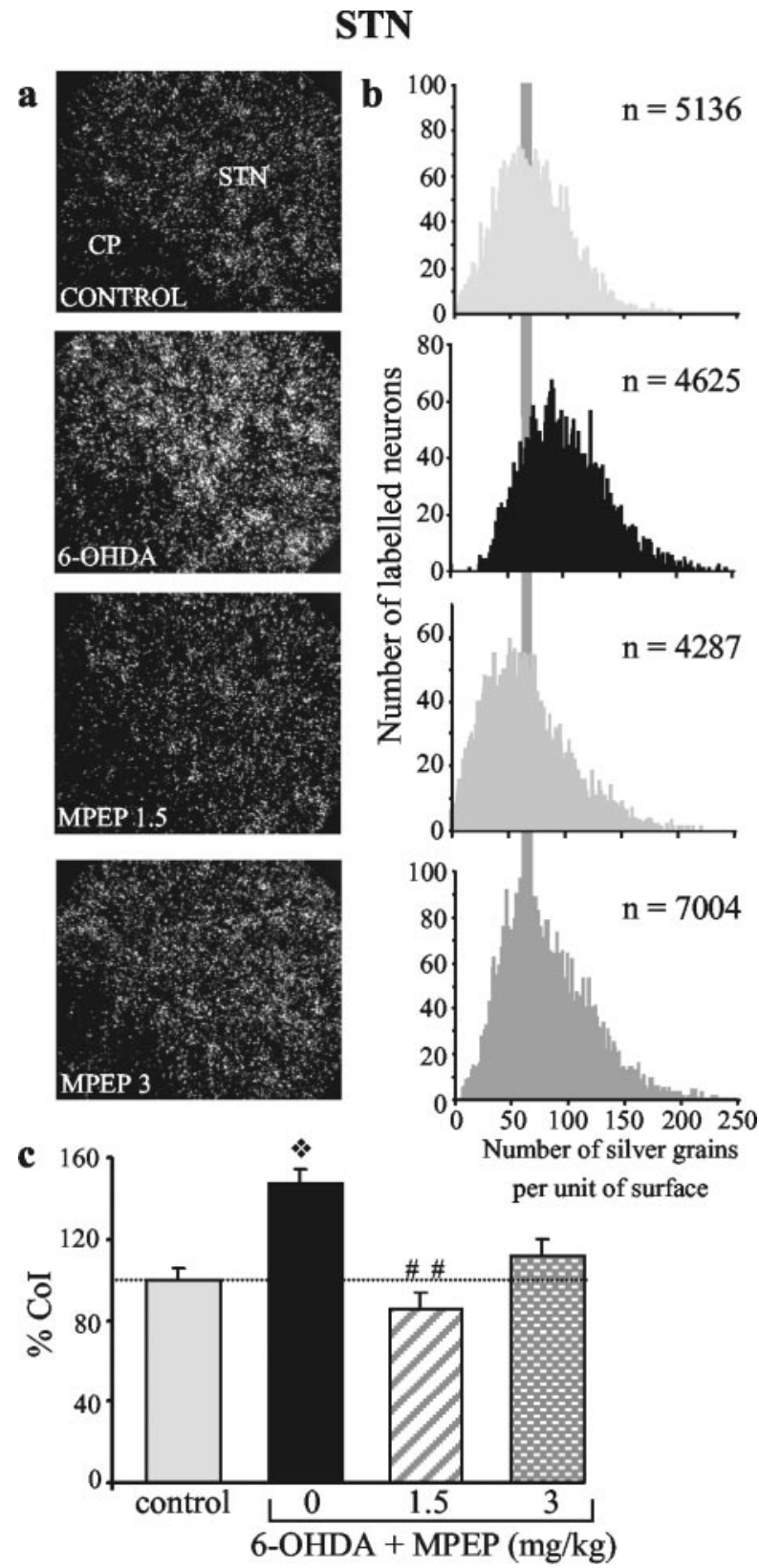

Figure 3. Chronic treatment with MPEP reverses the DA lesion-induced increase in Col gene expression in the STN. Photomicrographs ( $a$ ) taken under dark-field epi-illumination and histograms $(b)$ of frequency distribution of labeling, showing the effects of DA lesion without or with subsequent treatment with MPEP. The lesion $(n=6)$ induces an increase in intraneuronal labeling, confirmed by a shift to the right of the distribution curve (toward the higher levels), that is no longer observed after MPEP treatment at the doses of $1.5 \mathrm{mg} / \mathrm{kg}(n=6)$ and $3 \mathrm{mg} / \mathrm{kg}$ $(n=8)$. c, Histograms representing the mean number of silver grains per labeled neuron in each experimental condition expressed as percentage \pm SEM of control $(n=6)$. Statistical comparisons were performed using a one-way ANOVA, followed by Scheffé's test. $<<0.01$, compared with the control group; \#\#p $<0.01$, compared with values obtained in animals with the DA lesion alone.

\section{Model of early-stage PD}

The partial 6-OHDA-induced lesions produced a restricted DA denervation to the dorsal and lateral part of the striatum (corresponding to the putamen area in primates), and only slight, or no, DA depletion in the ventromedial part of the striatum (comparable with the caudate nucleus in primates). This restricted degeneration pattern reflects, therefore, the preferential DA loss in the putamen observed using positron emission tomography and single-photon emission computed tomography imaging studies of patients with early PD symptoms (Guttman et al., 1997; Ma et al., 2002), whereas in advanced stages of the disease the DA denervation reaches $60-90 \%$ in the caudate nucleus and is still more pronounced in the putamen. In the behavioral task, the lesioned animals showed a marked impairment of motor performance expressed as a long-lasting increase in delayed responses and RT, which are homologous to the akinetic deficits observed in the human pathology (Evarts et al., 1981; Pullman et al., 1988). Akinesia, the cardinal symptom of PD, is thought to result from abnormal activation of the STN and subsequent overactivity of basal ganglia output structures, the $\mathrm{SNr}$ and $\mathrm{EP}$. Most of the neurochemical data in the literature supporting this view have been obtained in the hemiparkinsonian rat model involving extensive (over 90\% DA depletion) unilateral lesions of nigrostriatal DA neurons (Herrero et al., 1996; Vila et al., 1996, 1997). Strikingly, we show here that bilateral and partial DA lesions lead to a dramatic increase (nearly 50\%) in gene expression of the metabolic marker CoI in the STN. To our knowledge, this finding provides the first evidence that the abnormal activation of the STN occurs when the DA depletion is moderate and affects only the putamen area. Compared with previous data showing no or slight increase in CoI mRNA expression in the STN after extensive striatal denervation (Vila et al., 2000; Salin et al., 2002), our results further suggest that STN reactivity may be even more pronounced at early, rather than late, stages of $\mathrm{PD}$. These results support the view that therapeutic strategies aimed at inactivating the STN in PD patients could be effective in early stages of the pathology. Moreover, the increase in STN metabolic activity was associated with a differential reactivity of the two major targets of the STN (Kita and Kitai, 1987; Parent and Hazrati, 1995). The late reactivity of the EP neurons during the time course of the disease may be related to dyskinetic symptoms associated with the longterm L-DOPA treatment (Krack et al., 1998).

\section{mGluR5 antagonist reverses akinetic deficits}

Both in situ hybridization and immunohistochemical data have shown significant expression of mRNA and protein for both mGluR1 and mGluR5 (group I mGluRs) in basal ganglia structures, particularly in the STN, and its output targets (i.e., EP and SNr) (Testa et al., 1994; Shigemoto and Mizuno, 2000). Recent studies have shown that activation of group I mGluRs (mGluR1 and mGluR5) produces a direct excitation of neurons in the STN mediated selectively by mGluR5 that further potentiates NMDAinduced activation of STN neurons (Awad et al., 2000; Marino et al., 2001). This suggests that mGluR5 antagonists may be beneficial in reducing the overactivity of STN neurons, ultimately providing symptomatic relief in PD. The present data raise functional arguments in favor of this hypothesis by showing that chronic systemic MPEP treatment at low doses suppresses the motor deficits induced by a striatal DA lesion, with no additional behavioral side effects. This lack of undesirable effects is further supported by recent studies reporting the effects of MPEP on locomotor activity, rotarod, or muscle rigidity (Spooren et al., 2000; Ossowska et al., 2001) and demonstrating no major debilitating motor effects such as ataxia or sedation in doses up to 100 $\mathrm{mg} / \mathrm{kg}$, such as those reported after treatment with NMDA receptor antagonists. Because MPEP has recently been described as an allosteric potentiator of mGluR4 (Mathiesen et al., 2003), one cannot exclude that the observed effects of MPEP may, in part, be caused by an agonist action of the mGluR5 antagonist on this group III mGluRs subtype. Furthermore, additional anatomical and electrophysiological data also raise the possibility that 


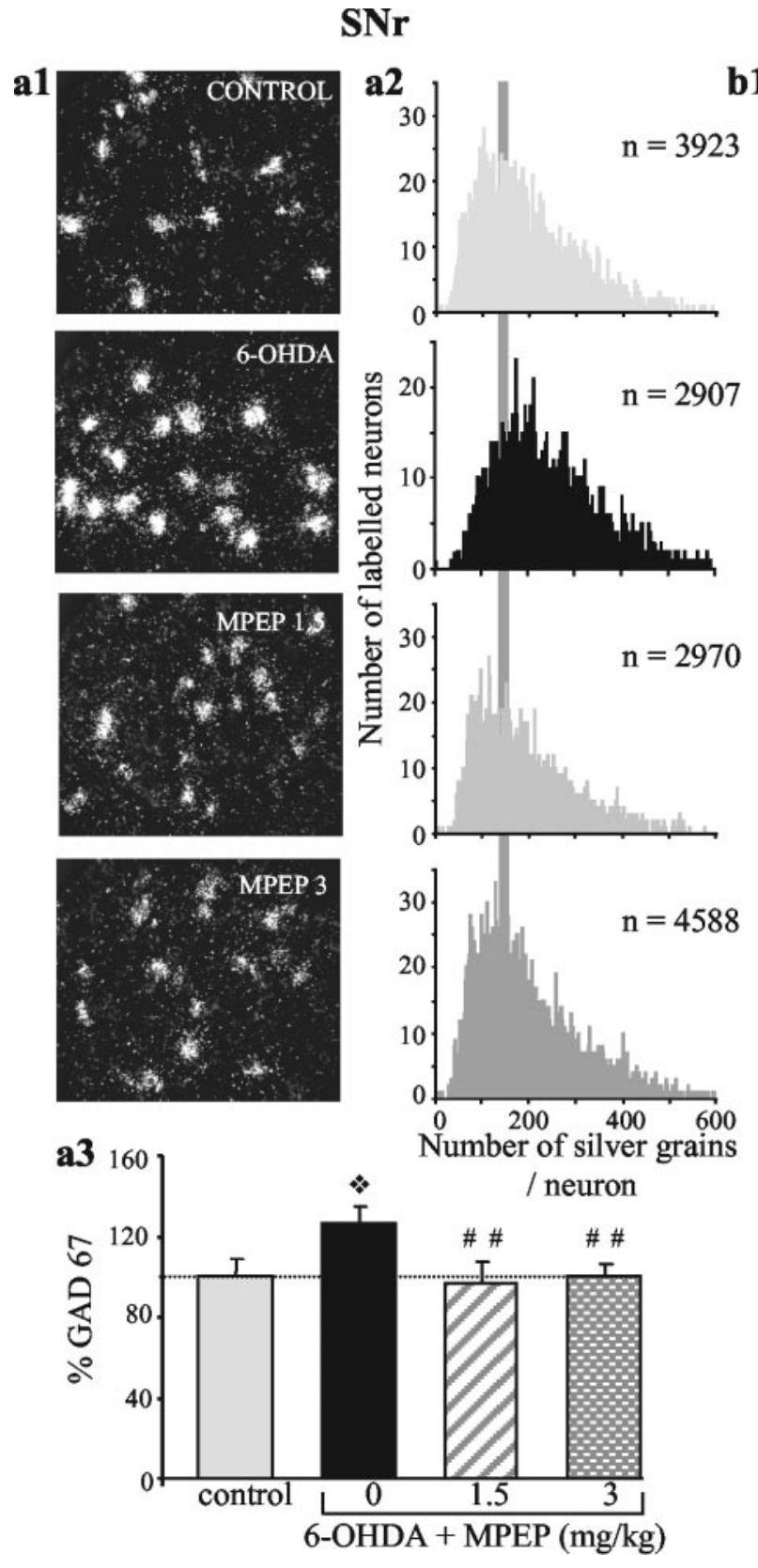

\section{EP}
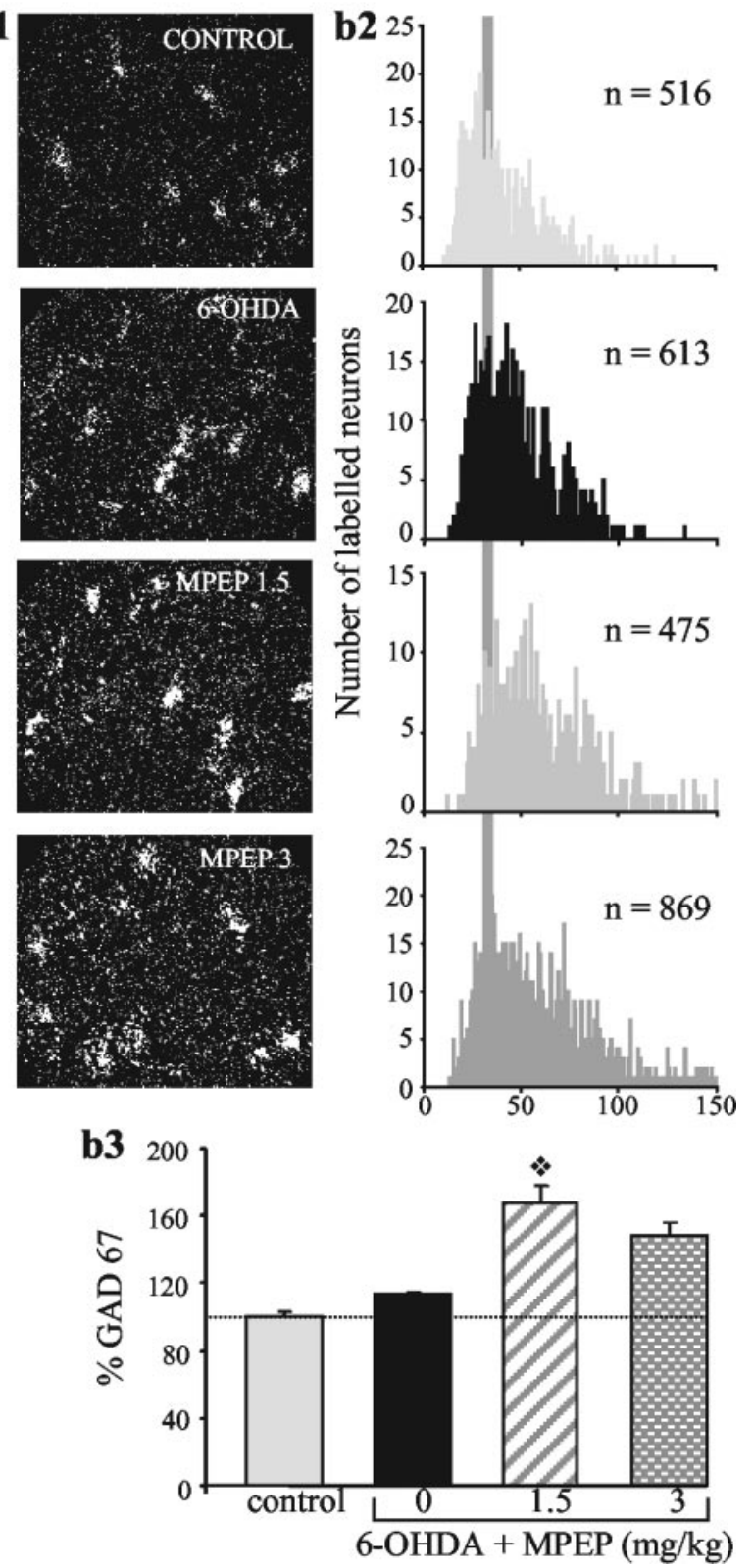

Figure 4. Chronic treatment with MPEP differentially affects gene expression of GAD67 in the SNr and EP of animals with the DA lesion. Photomicrographs (a1, b1) taken under dark-field epi-illumination and histograms $(a 2, b 2)$ of frequency distribution of labeling, showing the effects of DA lesion without or with subsequent treatment with MPEP. The lesion induces an increase in intraneuronal labeling in the SNr $(n=7)$, confirmed by a shift to the right of the distribution curve (toward the higher levels), without affecting labeling in EP neurons ( $n=7)$. MPEP treatment reverses the lesion-induced increase in the $\mathrm{SNr}$ ( $n=6$ at $1.5 \mathrm{mg} / \mathrm{kg} \mathrm{MPEP}$ and $n=9$ at $3 \mathrm{mg} / \mathrm{kg} \mathrm{MPEP}$; distribution curve similar to control) while producing an overexpression in EP neurons ( $n=$ 5 at $1.5 \mathrm{mg} / \mathrm{kg} \mathrm{MPEP}$ and $n=8$ at $3 \mathrm{mg} / \mathrm{kg}$ MPEP; distribution shifted to the right). $a 3, b 3$, Histograms representing the mean number of silver grains per labeled neuron in each experimental condition expressed as percentage \pm SEM of corresponding controls ( $n=7$ for SNr and $n=6$ for EP). Statistical comparisons were performed using a one-way ANOVA, followed by Scheffé's test. $\star p<0.05$, compared with control values; \#\# <0.01, compared with values obtained in animals with the DA lesion alone.

mGluR4 agonists may have antiparkinsonian effects. Although this possibility cannot be excluded, it is unlikely that the doses of MPEP used in this study (below $10 \mu \mathrm{M}$ ) act nonselectively to potentiate mGluR4, because Anderson et al. (2002) recently demonstrated a large discrepancy between MPEP potency at mGluR5 and mGluR4. Moreover, the behavioral benefit of MPEP treatment is associated with a reversal of the metabolic response of the STN to DA denervation. This suggests that the STN is a preferential target of MPEP treatment, although this study does not allow a firm conclusion as to whether MPEP acts directly on STN neurons or indirectly through its afferents. How- ever, recent compelling evidence supports the selective action of MPEP on the STN, because Phillips and Maidment (2002) reported that intracerebral injection of MPEP directly in the STN was able to counteract the forelimb asymmetries elicited by a unilateral DA denervation. In addition to its preferential action in the STN, MPEP could also directly act on the GABAergic neurons of the SNr. Indeed, although mGluR1 and mGluR5 have been found to be functionally dissociated at the level of the SNr and the STN in normal conditions, both receptors act synergistically to regulate neuronal activity of these two structures in pathological conditions (Marino et al., 2002). Thus, in the present model, 

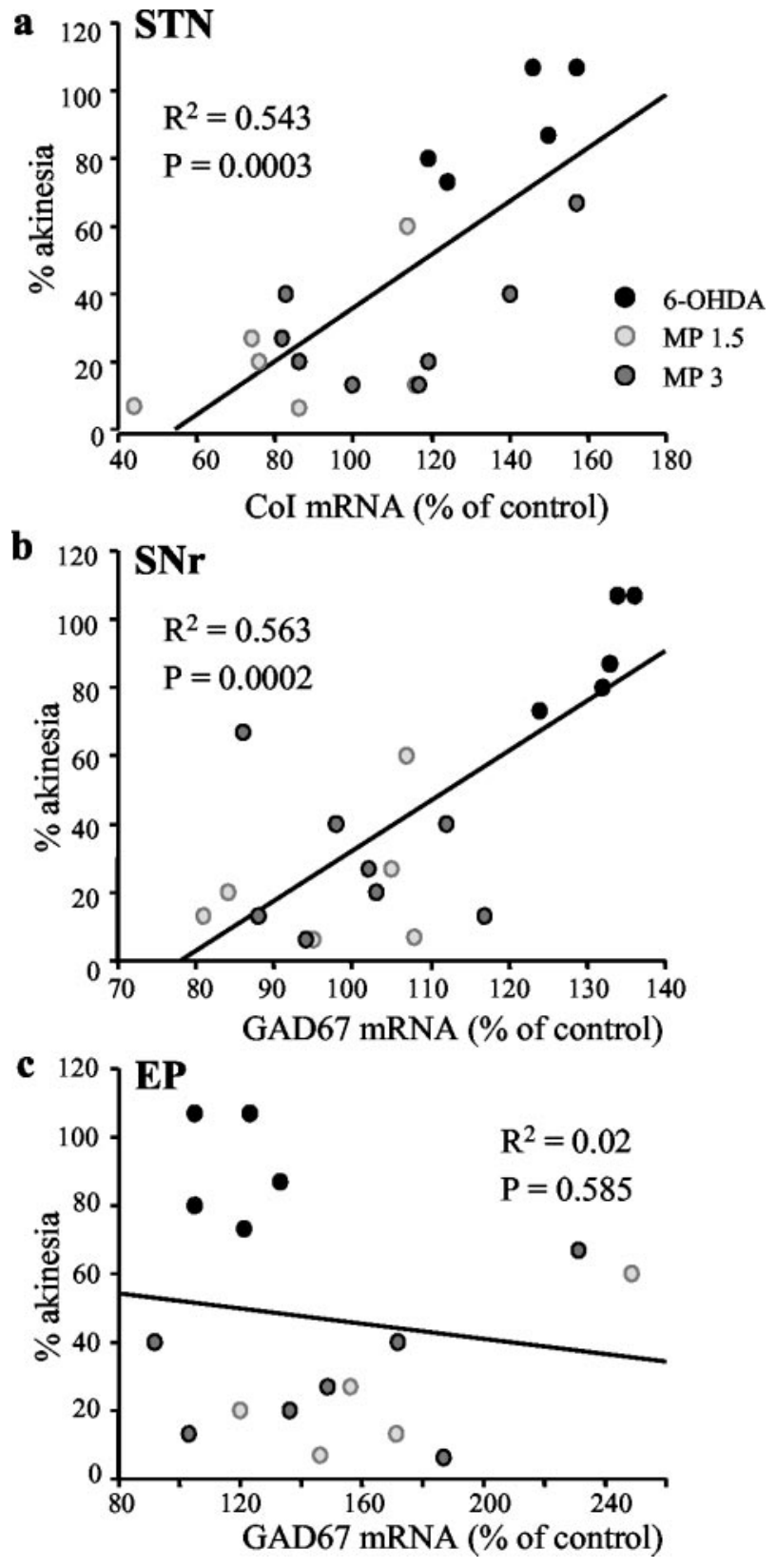

Figure 5. Correlations between akinetic deficit, expressed as the number of delayed responses, and changes in gene expression of Col mRNA in the STN ( $a$ ) and of GAD67 in the SNr $(b)$ and $\mathrm{EP}(c)$. Each point represents the difference in the number of delayed responses between experimental and control scores, expressed as percentage of control, with respect to percentage of change in mRNA levels in individual animals from the different experimental groups. Cellular changes in the STN and SNr, but not in EP, are significantly correlated with the behavioral deficit.

MPEP could directly influence these regulatory mechanisms at the level of the SNr. We also demonstrate a difference between the effects induced by MPEP in the SNr as compared with the EP. Indeed, whereas MPEP counteracts the DA-induced increase of neuronal GABAergic activity, indexed by the GAD67 mRNA expression in the $\mathrm{SNr}$, this compound elicits an increase of the same marker in the EP. Our findings support the hypothesis that $\mathrm{SNr}$ neurons are preferentially regulated by the STN and that EP activity is not related to the recovery of motor function produced by MPEP treatment in the rat model of early PD. We cannot exclude, however, that the EP could be involved in other aspects of motor control that were not investigated in our study. Regarding the differential and opposite effects obtained both by MPEP treatment and the lesion-induced cellular changes in the output structures, these data also suggest that in early stages of the disease, the $\mathrm{SNr}$ and EP are not subject to global regulation of the subthalamo-nigral or subthalamo-pallidal neural network, but, instead, could be controlled by a local regulation of glutamate activity on mGluR5.

\section{STN and $\mathrm{SNr}$, but not EP, preferentially mediate akinetic deficits}

Examining the cellular bases of the akinetic deficits observed in the rat model of early $\mathrm{PD}$, our study demonstrates that akinetic deficit scores are significantly correlated with changes in neuronal metabolic activity in the STN and SNr, but not in the EP. These data suggest that the akinetic symptoms are mediated by STN activity via the SNr. The lack of correlation between EP activity and akinesia is unlikely to be a rodent species-specific phenomenon because it has been reported previously, using a primate model of $\mathrm{PD}$, that improvement of akinetic deficits after STN lesion is associated with normalization of neuronal activity in the SNr, but not in the GPi (Guridi et al., 1996). In conclusion, our results provide the first evidence that the STN and SNr, and, hence, the subthalamo-nigral network, could be preferentially involved in the early symptomatic stages of PD. Moreover, we argue that selective mGluR5 antagonists may offer a valuable approach for the future treatment of $\mathrm{PD}$, particularly in the first steps of the disease.

\section{References}

Amalric M, Berhow M, Polis I, Koob GF (1993) Selective effects of low-dose D2 dopamine receptor antagonism in a reaction-time task in rats. Neuropsychopharmacology 8:195-200.

Amalric M, Baunez C, Nieoullon A (1995a) Does the blockade of excitatory amino acid transmission in the basal ganglia simply reverse reaction time deficits induced by dopamine inactivation? Behav Pharmacol 6:508-519.

Amalric M, Moukhles H, Nieoullon A, Daszuta A (1995b) Complex deficits on reaction time performance following bilateral intrastriatal 6-OHDA infusion in the rat. Eur J Neurosci 7:972-980.

Anderson JJ, Rao SP, Rowe B, Giracello DR, Holtz G, Chapman DF, Tehrani L, Bradbury MJ, Cosford NDP, Varney MA (2002) $\left[{ }^{3} \mathrm{H}\right]$ Methoxymethyl-3[(2-methyl-1,3-thiazol-4-yl)ethynyl]pyridine binding to metabotropic glutamate receptor subtype 5 in rodent brain: in vitro and in vivo characterization. J Pharmacol Exp Ther 303:1044-1051.

Awad H, Hubert GW, Smith Y, Levey AI, Conn PJ (2000) Activation of metabotropic glutamate receptor 5 has direct excitatory effects and potentiates NMDA receptor currents in neurons of the subthalamic nucleus. J Neurosci 20:7871-7879.

Baunez C, Nieoullon A, Amalric M (1994) N-methyl-D-aspartate receptor blockade impairs behavioral performance of rats in a reaction time task: new evidence for glutamatergic-dopaminergic interactions in the striatum. Neuroscience 61:521-531.

Benabid AL, Krack PP, Benazzouz A, Limousin P, Koudsie A, Pollak P (2000) Deep brain stimulation of the subthalamic nucleus for Parkinson's disease: methodologic aspects and clinical criteria. Neurology 55:S40-S44.

Breysse N, Baunez C, Spooren W, Gasparini F, Amalric M (2002) Chronic but not acute treatment with a metabotropic glutamate 5 receptor antagonist reverses the akinetic deficits in a rat model of parkinsonism. J Neurosci 22:5669-5678.

Chase TN, Oh JD (2000) Striatal dopamine- and glutamate-mediated dysregulation in experimental parkinsonism. Trends Neurosci 23:S86-S91.

DeLong MR (1990) Primate models of movement disorders of basal ganglia origin. Trends Neurosci 13:281-285.

Evarts EV, Teravainen H, Calne DB (1981) Reaction time in Parkinson's disease. Brain 104:167-186.

Gasparini F, Lingenhohl K, Stoehr N, Flor PJ, Heinrich M, Vranesic I, Biollaz M, Allgeier H, Heckendorn R, Urwyler S, Varney MA, Johnson EC, Hess SD, Rao SP, Sacaan AI, Santori EM, Velicelebi G, Kuhn R (1999) 2-Methyl-6-(phenylethynyl)-pyridine (MPEP), a potent, selective and 
systemically active mGlu5 receptor antagonist. Neuropharmacology 38:1493-1503.

Greenamyre JT, O'Brien CF (1991) N-methyl-D-aspartate antagonists in the treatment of Parkinson's disease. Arch Neurol 48:977-981.

Guridi J, Herrero MT, Luquin MR, Guillen J, Ruberg M, Laguna J, Vila M, Javoy-Agid F, Agid Y, Hirsch E, Obeso JA (1996) Subthalamotomy in parkinsonian monkeys. Behavioral and biochemical analysis. Brain 119:1717-1727.

Guttman M, Burkholder J, Kish SJ, Hussey D, Wilson A, DaSilva J, Houle S (1997) [11C]RTI-32 PET studies of the dopamine transporter in early dopa-naive Parkinson's disease: implications for the symptomatic threshold. Neurology 48:1578-1583.

Herrero MT, Levy R, Ruberg M, Luquin MR, Villares J, Guillen J, Faucheux B, Javoy-Agid F, Guridi J, Agid Y, Obeso JA, Hirsch EC (1996) Consequence of nigrostriatal denervation and L-dopa therapy on the expression of glutamic acid decarboxylase messenger RNA in the pallidum. Neurology 47:219-224.

Javitch JA, Strittmatter SM, Snyder SH (1985) Differential visualization of dopamine and norepinephrine uptake sites in rat brain using. J Neurosci 5:1513-1521.

Kita H, Kitai ST (1987) Efferent projections of the subthalamic nucleus in the rat: light and electron microscopic analysis with the PHA-L method. J Comp Neurol 260:435-452.

Krack P, Pollak P, Limousin P, Hoffman D, Xie J, Benazzouz A, Benabid AL (1998) Subthalamic nucleus or internal pallidal stimulation in young onset Parkinson's disease. Brain 121:451-457.

Lievens JC, Dutertre M, Forni C, Salin P, Kerkerian-Le Goff L (1997) Continuous administration of the glutamate uptake inhibitor L-transpyrrolidine-2,4-dicarboxylate produces striatal lesion. Brain Res Mol Brain Res 50:181-189.

Lorenc-Koci E, Konieczny J, Wolfarth S (1998) Contribution of the glycine site of NMDA receptors in rostral and intermediate-caudal parts of the striatum to the regulation of muscle tone in rats. Brain Res 793:315-320.

Ma Y, Dhawan V, Mentis M, Chaly T, Spetsieris PG, Eidelberg D (2002) Parametric mapping of. Synapse 45:125-133.

Marino MJ, Wittmann M, Bradley SR, Hubert GW, Smith Y, Conn PJ (2001) Activation of group I metabotropic glutamate receptors produces a direct excitation and disinhibition of GABAergic projection neurons in the substantia nigra pars reticulata. J Neurosci 21:7001-7012.

Marino MJ, Awad-Granko H, Ciombor KJ, Conn PJ (2002) Haloperidolinduced alteration in the physiological actions of group I mGlus in the subthalamic nucleus and the substantia nigra pars reticulata. Neuropharmacology 43:147-159.

Mathiesen JM, Svendsen N, Bräuner-Osborne H, Thomsen C, Ramirez MT (2003) Positive allosteric modulation of the human metabotropic receptor 4 (hmGluR4) by SIB-1893 and MPEP. Br J Pharmacol 138:1026-1030.

Ossowska K, Lorenc-Koci E, Wolfarth S (1994) Antiparkinsonian action of MK-801 on the reserpine-induced rigidity: a mechanomyographic analysis. J Neural Transm Park Dis Dement Sect 7:143-152.

Ossowska K, Lorenc-Koci E, Schulze G, Wolfarth S (1996) The influence of dizocilpine (MK-801) on the reserpine-enhanced electromyographic stretch reflex in rats. Neurosci Lett 203:73-76.

Ossowska K, Konieczny J, Wolfarth S, Wieronska J, Pilc A (2001) Blockade of the metabotropic glutamate receptor subtype 5 (mGluR5) produces antiparkinsonian-like effects in rats. Neuropharmacology 41:413-420.
Parent A, Hazrati LN (1995) Functional anatomy of the basal ganglia. II. The place of subthalamic nucleus and external pallidum in basal ganglia circuitry. Brain Res Rev 20:128-154.

Paxinos G, Watson C (1986) The rat brain in stereotaxic coordinates, Ed 2. Sydney: Academic.

Phillips JM, Maidment NT (2002) The subthalamic nucleus (STN) mediates the anti-Parkinsonian effect of MPEP in an animal model of Parkinson's disease. Paper presented at the 32nd Annual Meeting of the Society for Neuroscience, Orlando, FL, November.

Pullman SL, Watts RL, Juncos JL, Chase TN, Sanes JN (1988) Dopaminergic effects on simple and choice reaction time performance in Parkinson's disease. Neurology 38:249-254.

Rouse ST, Marino MJ, Bradley SR, Awad H, Wittmann M, Conn PJ (2000) Distribution and roles of metabotropic glutamate receptors in the basal ganglia motor circuit: implications for treatment of Parkinson's disease and related disorders. Pharmacol Ther 88:427-435.

Salin P, Hajji MD, Kerkerian-Le Goff L (1996) Bilateral 6-hydroxydopamineinduced lesion of the nigrostriatal dopamine pathway reproduces the effects of unilateral lesion on substance $\mathrm{P}$ but not on enkephalin expression in rat basal ganglia. Eur J Neurosci 8:1746-1757.

Salin P, Manrique C, Forni C, Kerkerian-Le Goff L (2002) High-frequency stimulation of the subthalamic nucleus selectively reverses dopamine denervation-induced cellular defects in the output structures of the basal ganglia in the rat. J Neurosci 22:5137-5148.

Schmidt WJ (1994) Behavioral effects of NMDA-receptor antagonists. J Neural Transm Suppl 43:63-69.

Shigemoto R, Mizuno N (2000) Metabotropic glutamate receptors-immunocytochemical and in situ hybridization analyses. In: Handbook of chemical neuroanatomy, Vol 18 (Ottersen OP, Storm-Mathisen J, eds), pp 63-98. New York: Elsevier Science.

Spooren WP, Gasparini F, Bergmann R, Kuhn R (2000) Effects of the prototypical mGlu(5) receptor antagonist 2-methyl-6-(phenylethynyl)pyridine on rotarod, locomotor activity and rotational responses in unilateral 6-OHDA-lesioned rats. Eur J Pharmacol 406:403-410.

Starr MS (1995) Glutamate/dopamine D1/D2 balance in the basal ganglia and its relevance to Parkinson's disease. Synapse 19:264-293.

Testa CM, Standaert DG, Young AB, Penney Jr JB (1994) Metabotropic glutamate receptor mRNA expression in the basal ganglia of the rat. J Neurosci 14:3005-3018.

Vila M, Herrero MT, Levy R, Faucheux B, Ruberg M, Guillen J, Luquin MR, Guridi J, Javoy-Agid F, Agid Y, Obeso JA, Hirsch EC (1996) Consequences of nigrostriatal denervation on the $\gamma$-aminobutyric acidic neurons of substantia nigra pars reticulata and superior colliculus in parkinsonian syndromes. Neurology 46:802-809.

Vila M, Levy R, Herrero MT, Ruberg M, Faucheux B, Obeso JA, Agid Y, Hirsch EC (1997) Consequences of nigrostriatal denervation on the functioning of the basal ganglia in human and nonhuman primates: an in situ hybridization study of cytochrome oxidase subunit I mRNA. J Neurosci 17:765-773.

Vila M, Perier C, Feger J, Yelnik J, Faucheux B, Ruberg M, Raisman-Vozari R, Agid Y, Hirsch EC (2000) Evolution of changes in neuronal activity in the subthalamic nucleus of rats with unilateral lesion of the substantia nigra assessed by metabolic and electrophysiological measurements. Eur J Neurosci 12:337-344. 